
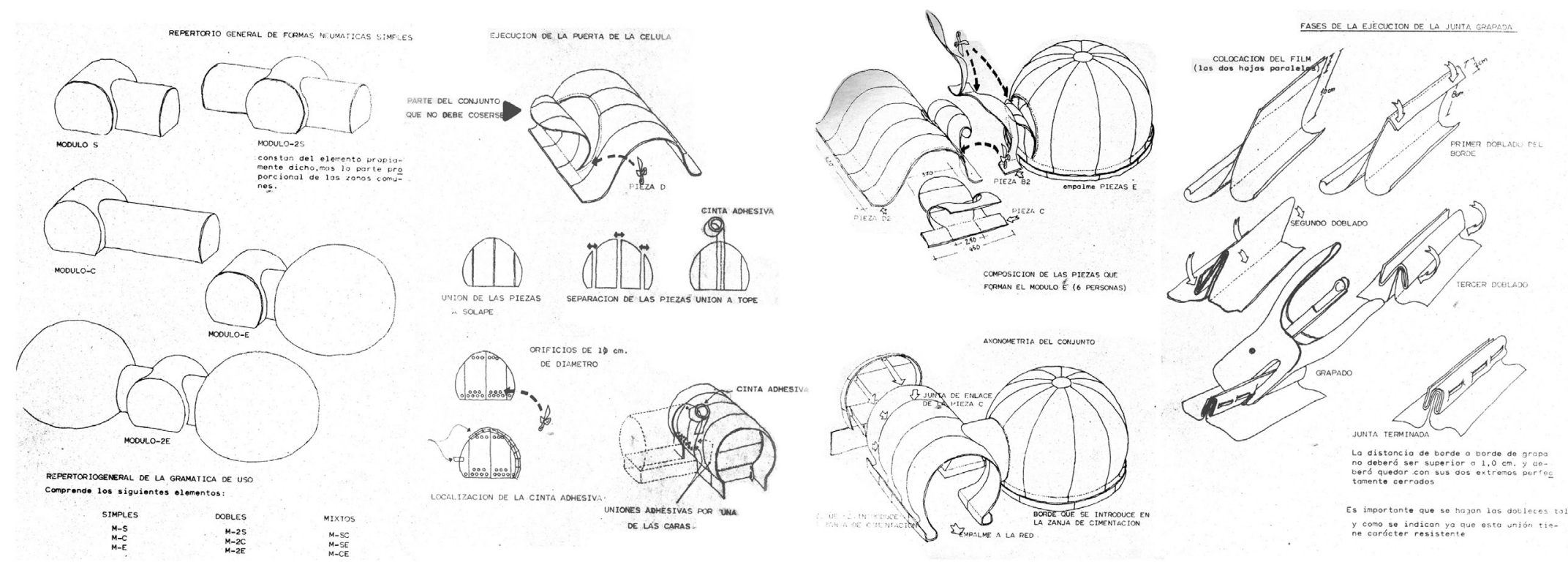

\section{Instant City}

Fernando Bendito, Carlos Ferrater, José Miguel de Prada Poole

Recibido 2018.06.19 ::: Aceptado 2018.06.22

DOI: 10.5821/palimpsesto.18.5660

n el año 1971 y con motivo del VII Congreso del International Council of Societies of Industrial Design (ICSID), la isla de lbiza (concretamente la cala Sant Miquel, al norte de la misma) acogió la Instant City, una ciudad efímera que se levantó, ocupó y desmanteló en poco más de un mes. Los entonces estudiantes de arquitectura Fernando Bendito y Carlos Ferrater se ofrecen a ADI/FAD -responsable de la organización del congreso- para encargarse del alojamiento de los cientos de estudiantes de diseño de todo el mundo que acudirían al congreso; su ofrecimiento es aceptado y se les proporciona un terreno donde acampar. Bendito y Ferrater se ponen en contacto con el arquitecto José Miguel de Prada Poole. experto en arquitectura neumática, el cual elabora un lenguaje mínimo que permitiría la construcción de una cobertura en un tiempo muy reducido y con un instrumental mínimo.

Pasados casi 50 años de este experimento, que acabó convirtiéndose en el símbolo del VII Congreso Internacional del ICSID, hablamos con Carlos Ferrater sobre sus luces y sombras, poniendo especial énfasis en la sorprendente vigencia que el emblemático proyecto conserva hoy en día.

PALIMPSESTO: ¿Por qué se produjo la Instant City en ese momento preciso?

Carlos Ferrater: Nosotros, como estudiantes de arquitectura, en aquel momento estábamos con la contestación política. En un momento dado consideramos que quizá el nivel de rebeldía o de propuesta social debía estar más basado en la creatividad y en aquello en lo que nosotros estábamos formándonos que en la lucha callejera, que también. Nos dimos cuenta de que el mundo se había transformado después de mayo del 68 en París, de Woodstock en el 69, de la isla del Wight en el 70, con todos aquellos movimientos de la música y el ocio como transformadores de la cultura de masas. Y en el 71 dijimos: en Ibiza el happening no será la música sino que será el diseño, la construcción, la arquitectura. Vimos la ocasión del congreso y dijimos: ¿nos dejan hacer el camping para los estudiantes? Tenían un terreno y 10000 pesetas, que nos fueron dando de 200 en 200 y que se fueron en el envío masivo del manifiesto. Este fue el motivo de por qué en aquel momento dos estudiantes de arquitectura de la Escuela decidimos romper con todo.
Cuando se habla de la Instant City, es frecuente el uso de la palabra Utopía, tal y como hizo el Macba titulando "La utopía es posible" la exposición retrospectiva de 2012. ¿Crees que este lema es fie a la voluntad de los que la ideasteis? ¿O pondrías más énfasis en la búsqueda del ocio necesario en mas enfasis en la busqueda del ocio necesa

Es evidente que las utopías no son realizables porque si no dejan de ser utopías, con lo cual es una contradicción decir que la ciudad instantánea fue una utopía. Cuando la utopía fue posible es un eslogan. Yo creo que la instant City fue un experimento de vida en comunidad en la que el trabajo era el medio de comunicación. Es decir, grapando y construyendo y creando una ciudad y unos espacios para vivir durante un tiempo llegábamos a una cultura del ocio, de la expresión formal, y la gente se comunicaba a través de grapar. Un millón de grapas. Y miles y miles de metros cuadrados de plástico con los que se construyó aquella ciudad. El ocio como expresión creativa de la vida a través del trabajo era para nosotros el leit motiv de toda esta historia.

Quizá el reglar la construcción en base a unos patrones -a pesar de que hubo excepcioneses lo que llevó a que la ciudad instantánea se estandarizara un poco en las reglas. Si hubiera sido más caótica seguramente hubiera estado más al quite de las asambleas que hacíamos y de cómo nos dividíamos el trabajo, de lo que era un happening contínuo de fiestas en la playa con los hinchables, etc. En cambio empezaron a aparecer reglas en el comportamiento de la gente que vivía en la ciudad, estableciendo una manera de entrar, unos horarios, no fumar, etc., y todas esas reglas provocaron que aquello que había sido una propuesta contra un congreso oficial, contra una manera de vivir y de expresarse, se convirtiera en una especie de ciudad pequeñoburguesa. Por ello, una parte de esta gente, con restos de plásticos y cañas, montamos en la ladera de la montaña otra pequeña ciudad, una protesta a la protesta. La otra, la original, tuvo la belleza de deshacerse como un gusanito, con los payeses locales cortando los hinchables para aprovecharlos en sus pajares. Y durante muchísimos años en el norte de lbiza encontrabas los pajares y contenedores agrícolas cubiertos de los casquetes y los cilindros, con aquellos colores fantásticos que perduraron durante años y años. Fue precioso ver cómo se deshinchaba la Instant y cómo, contra todo pronóstico, la ciudad se recicló. El recuerdo tiene también sus sombras, porque los primeros habitantes que vinieron de Barcelona con nosotros para ayudarnos a organizarlo todo ya no están: el sida, las drogas... En cambio también tiene muchas cosas muy positivas: cuando pienso en Benidorm, casi medio siglo después, el proyecto tiene la misma ilusión, y recupera aquel espíritu que se mueve entre dos hemisferios: uno es la imaginación, lo aleatorio, las formas del caos y las geometríoas de la complejidad; y otro el rigor, la disciplina, los maestros. Esta doble visión es lo que pude aprender de esa experiencia.

¿Qué continuidad tuvo esta experiencia con los inflables y la autoconstrucción?

Posteriormente a la Instant, Aiscondel (la empresa de plásticos que suministró todo el material para la Instant) montó un grupo con el que hicimos el pabellón de la feria del campo de Aiscondel, que era un hinchable curioso. Incluso el propio José Miguel de Prada llegó a vaticinar que no se hincharía, porque tenía esferas cóncavas y convexas, y creyó que la tensión tendería a deformarlo o a romper la membrana. Y no. Se mantuvo porque habíamos hecho una sección de la partes cóncavas en troncos de cono, que evitaba que se pudiera deformar. Con nosotros trabajó un profesor de geometría descriptiva de la escuela que nos ayudó y nos hizo todo el patronaje. Después hicimos un hinchable maravilloso en Benidorm, transparente, que me pidió un grupo hotelero para una exposición. Lo montamos y al cabo de una semana hubo una tempestad terrible, un viento desaforado, y se rajó. Hicimos también un juguete para niños, un paquete que incluía una esferita y un ventilador y los niños lo hinchaban y se convertía en una casita. Y hubo otros que no se hicieron, aquelló duró unos meses durante los cuales experimentamos con geodésicas y otras formas.

¿Por qué recuperar hoy, casi medio siglo después, la Instant City?

Yo creo que es muy positivo para los estudiantes y los jóvenes de hoy, que lo tienen todo tan reglado y con un panorama profesional muy difícil, pensar que a veces lo que puede parecer perder el tiempo no lo es. El tiempo siempre se recupera. Una experiencia como esta hoy sería muy difícil, porque en seguida vendrían los sabios, los ingenieros, los códigos técnicos, el fuego..., y difícilmente podría desarrollarse ese espíritu de lo desconocido, de la prueba.

Sin embargo, vamos hacia una sociedad en la que el ocio será cada vez más importante, y hay que encontrar formas de trabajar el ocio para poder vivir cada vez más años, teniendo en cuenta que la esperanza de vida no deja de aumentar. Una experiencia como la Instant, por tanto, tiene esa doble vertiente de la juventud como experimento y de la vejez como desarrollo, de encontrar sistemas en los cuales el trabajo asociado al ocio sea la forma de comunicación entre la gente. 
En el sentido de las agujas del reloj: un arbol en en interior de una estera; interior habitado forma de tricornio; interior de una esfera; mujeres locales observando la construt
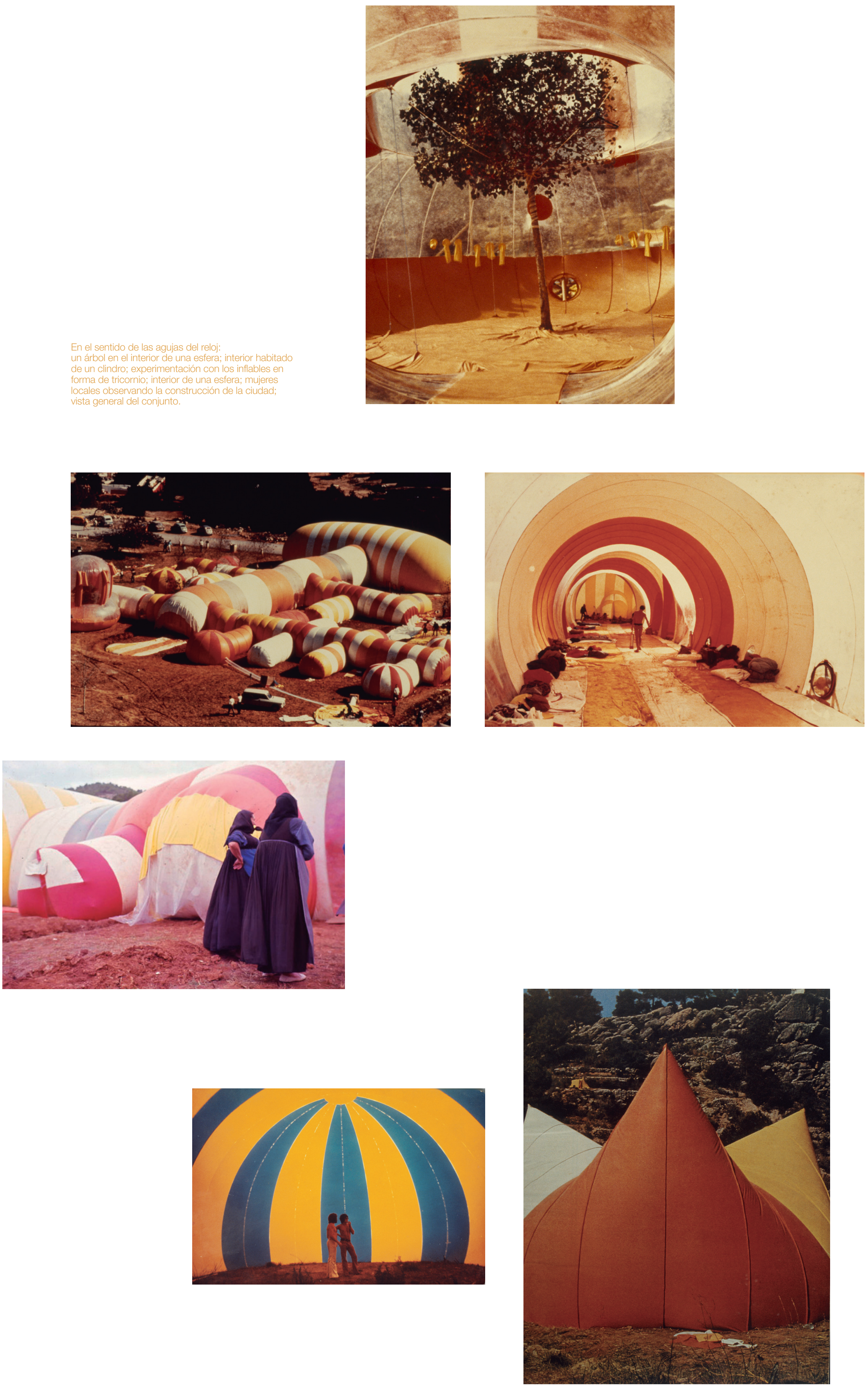